Working Paper n. 06 - 2015

\title{
GENDER DIFFERENCES IN REACTION TO PSYCHOLOGICAL PRESSURE: EVIDENCE FROM TENNIS PLAYERS
}

\author{
Maria De Paola \\ Dipartimento di Economia, \\ Statistica e Finanza \\ Università della Calabria \\ Ponte Pietro Bucci, Cubo 1/C \\ Tel.: +390984 492459 \\ Fax: +390984 492421 \\ e-mail:m.depaola@unical.it
}

\author{
Vincenzo Scoppa \\ Dipartimento di Economia, \\ Statistica e Finanza \\ Università della Calabria \\ Ponte Pietro Bucci, Cubo 1/C \\ Tel.: +390984 492464 \\ Fax: +390984 492421 \\ e-mail: v.scoppa@unical.it
}

\section{Dicembre 2015}

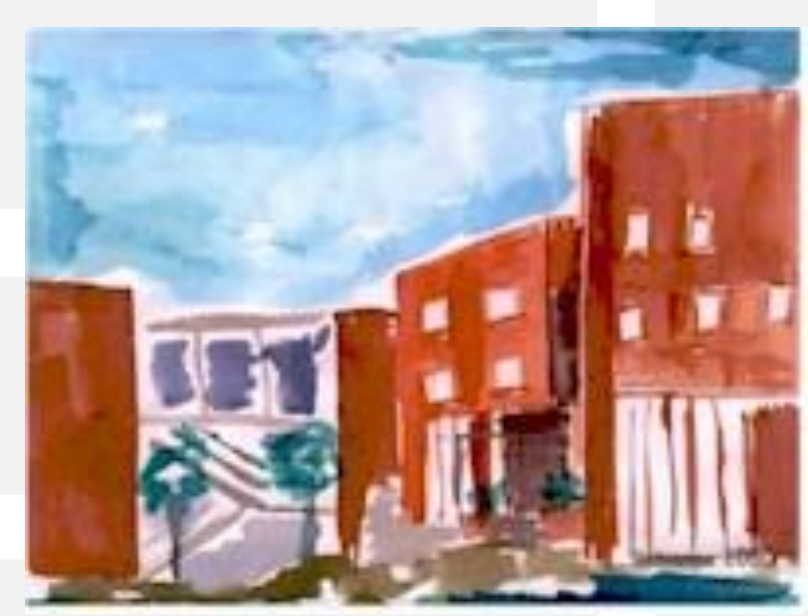




\title{
Gender Differences in Reaction to Psychological Pressure: Evidence from Tennis Players
}

\author{
Maria De Paola ${ }^{a, b}$, Vincenzo Scoppa $a^{a, b *}$ \\ ${ }^{a}$ Department of Economics, Statistics and Finance, University of Calabria \\ ${ }^{b}$ Institute for the Study of Labor (IZA), Bonn
}

This version: $18 / 12 / 2015$

\begin{abstract}
Using data on about 35,000 professional tennis matches, we test whether men and women react differently to psychological pressure arising from the outcomes of sequential stages in a competition. We show that, with respect to males, females losing the first set are much more likely to play poorly the second set, choking under the pressure of falling behind and receiving negative feedback. The gender differential is stronger in high stakes matches. On the other hand, when players are tied in the third set we do not find any gender difference in players' reactions: this suggests that females do not tend to choke if they do not lag behind. These results are robust controlling for measures of abilities and fitness of players, such as players' rankings, players' ex-ante winning probability, players' rest, players' and tournaments' fixed effects.
\end{abstract}

Keywords: Gender Differences; Psychological Pressure; Choking under Pressure; Feedback; Tennis

JEL classifications: J16; D03; L83

\footnotetext{
*E-mail addresses: m.depaola@unical.it (M. De Paola); v.scoppa@unical.it (V. Scoppa). We would like to thank Guido de Blasio, Francesca Gioia, Sabrina Giordano, Michael Jetter, Claudio Lucifora, Paolo Naticchioni, Federica Origo, Francesco Pastore, Michela Ponzo and seminar participants to 2015 Italian Association of Labor Economists Conference (Cagliari) for useful comments and suggestions.
} 


\section{Introduction}

The gender gap in labor market outcomes and the so called "glass ceiling", preventing women from rising to top positions, have long attracted the attention of economists and have been traditionally explained considering differences in human capital and taste-based or statistical discrimination. A recent strand of the literature moves beyond the traditional theories by considering that females might have different psychological attitudes and different preferences with respect to males (Bertrand, 2011; Croson and Gneezy, 2009; Azmat and Petrongolo, 2014). A robust evidence shows that females are more averse to risk and tend to shy-away from competitive settings (Niederle and Vesterlund, 2011) and these differences may be responsible for a significant share of gender gaps in economic outcomes.

The aversion of women to competition could be related to a variety of psychological factors - lower self-confidence, aversion to negative feedback, difficulties to cope with pressure - which have been little investigated on the field. Croson and Gneezy (2009) point out that women show stronger emotional reactions: they experience more stress, fear or dread when a risk of a negative outcome is present (Brody, 1993; Fujita, Diener and Sandvik, 1991; Fehr-Duda, de Gennaro and Schubert (2006), Grossman and Wood 1993). These stronger emotions might depend on gender differences in perceived pressure: women might feel a higher level of pressure than men and, as a consequence, they might experience more anxiety. Furthermore, Roberts and Nolen-Hoeksema (1989) show that females react poorly to negative information about how they did compared to others, perceiving negative feedback to be more informative about their abilities and Johnson and Helgeson (2002) find that women's self-esteem significantly dropped after negative feedback.

Psychological pressure may be associated to many different situations. For instance, pressure might arise from situations in which high stakes are in place, when the circumstances are difficult and the risk of failure is high, when individuals have to cope with the emotions following a failure. As suggested by Gill and Prowse (2014), gender differences could emerge in response to positive and negative outcomes in multistages competitions. The psychological feelings of the individuals (such as stress or excitement) might change with the stage of the competition and might be handled differently according to gender. These feelings have long been considered by the theory of psychological momentum. While the winner experiments excitement and a higher level of self-confidence, the loser is likely to experience discouragement.

To understand the relevance of these psychological responses it has to be considered that in many real life situations individuals face sequential competitive environments in which outcomes depend on relative performance and participants receive feedback on ongoing outcomes. Firms and public organizations, such as universities, governments, use contests to promote individuals or to reward them. The competition arising in political elections or the competition to land a good job represent contests with similar characteristics. As many of these competitions have a sequential structure, the outcome of one stage can influence individual 
performance in subsequent stages and the psychological reactions of participants can affect the final outcome.

In this paper we aim to provide evidence from the field on whether males and females react differently to the psychological pressure deriving from the feedback on own and other's performance and from previous outcomes of an on-going competition that makes its interim state balanced or unbalanced. To investigate gender differences in response to ongoing outcomes and feedback we use data on about 35,000 professional tennis matches from 2007 to 2014. Tennis is a particularly well suited sport to investigate the connection between psychological feelings and performance. Tennis experts and coaches consider the player's emotional stability - "one's ability to handle frustration, tension, and anxiety while on the tennis court" - as one of the key components of success (Giampaolo and Levey, 2013). ${ }^{1}$

We focus on best-of-three matches. The outcome of the first set gives feedback on how well players are playing, on their physical fitness, on luck, and, importantly, it changes the interim state of the match, that is, one of the player will stay ahead while the opponent will fall behind. Being behind and feeling the pressure to succeed in the second set might affect performance and lead those players who are less able to handle these emotions to choke. According to some psychological studies (see, among others, Roberts and Nolen-Hoeksama, 1989, Dweck, 2000; Lundgren and Rudawsky 1998), women tend to interpret a negative signal as an indicator of their self-worth rather than simply as a specific and episodic event. This can affect women's self-confidence bringing to confidence traps from which it is hard to recover.

On the other hand, if the match does not end with the second set, so that players are tied having won one game each, there is a new feedback (in the opposite direction of the first feedback) but the state of the match is balanced. As a consequence, the feelings of anxiety and fear deriving from losing the match might be less pronounced and it is worthwhile to verify if men and women react differently in this balanced context.

Controlling for players' rankings, for the ex-ante winning probabilities and for a number of match characteristics, our results show that losing the first set produces a negative effect on the second set performance for both men and women, but the effect is much stronger for women. Male players losing the first set lose about 1.2 games more than their opponent in the second set, whereas females losing the first set tend to lose about 1.8 games more. Obviously, we cannot claim that the impact of the first set outcome on the subsequent performance is causal (a number of omitted factors might affect the outcomes of sequential sets in a similar way), but we point out that the effect of the first set outcome is much more pronounced on females than on males.

\footnotetext{
${ }^{1}$ In his wonderful account of a famous tennis match the journalist and writer John McPhee explains "...the first point played in any set was of considerable psychological importance. A perceptible edge can go to the winner of that point. As the case may be, that one point can restore, maintain, deflate, or destroy confidence. Confidence goes back and forth across a tennis net much like the ball itself" (McPhee, J., 1969, "Levels of the game", p. 32-33). 
In contrast, we do not find any statistically significant gender difference in players' responses during the third set as a reaction to the first two sets' outcomes. In particular, the player who wins the second set tend to perform slightly better in the third set, but this occurs for both men and women.

This evidence suggests that males and females react differently to an outcome that changes the balance of the match, but react similarly to the immediate emotions following a win/loss when the result is balanced. This could depend on the fact that when females lag behind they experience greater stress and discouragement compared to men leading to a "never catch up syndrome", while when they feel equal to their opponent are more capable to manage emotions.

Our findings remain substantially the same also when we restrict the sample to those matches in which the first set was close (the winner either won seven games to five or won the tie-breaking game) and when we only consider matches in which players had a very similar probability of winning, implying that the reactions are not driven by differences in unobserved ability.

We also find that when stakes are higher, as in the final rounds of a tournaments, the gender difference in the effect of losing the first set becomes larger: while males performing in high stakes matches are less affected by the first set result, women tend to significantly worsen their performance compared to what happens in lower stakes matches. This is probably due to the high pressure faced in these high stakes matches.

Our work is related to a number of recent works analyzing the effects of psychological pressure on individuals' performance, although most of these studies do not consider gender differences. Apesteguia and Palacios-Huerta (2010) show that being first-mover in penalty shoot-outs in soccer competitions increases the probability of winning: kicking second (or when the team is lagging behind) puts soccer players under psychological pressure since they are more likely to face the situation of lagging instead of that of leading in the partial score. On this aspect see also the works of Baumeister (1985), Dohmen (2008), Kocher, Lenz and Sutter (2012), Feri, Innocenti and Pin (2013).

Furthermore, our analysis is related to the literature investigating the phenomenon of "momentum" for the winner of a stage and that of "discouragement" for the losing player, which has relied both on laboratory experiments and on the use of sports data.

Lab experiments investigating gender differences in "momentum" have found mixed results. ${ }^{2}$ Gill and Prowse (2014), in a ten round lab experiment in which participants have to provide work effort, find strong gender differences in the reaction to previous wins and losses. Losses determine a reduction in effort for women, while for men productivity is affected only when the prize at stake is large enough. Buser (2014) implements an experiment in which participants compete in a two-person tournament and after having been informed on the outcome of the competition have to decide on a performance target for a second round. $\mathrm{He}$ finds that while men losing the first round go for a more challenging target but perform worse in the second

\footnotetext{
${ }^{2}$ Mago, Sheremeta, and Yates (2013) found evidence consistent with the existence of a strategic momentum, while Fu, $\mathrm{Ke}$, and Tan (2013) found results supporting a negative momentum effect such that trailing contestants provide more effort to catch up with leading contestants.
} 
round, women do not change their target, but lower their performance. Wozniak, Harbaugh and Mayr (2014) in an experiment in which participants have to solve math and word tasks show that providing information on relative performance eliminates gender differences in choices by inducing high ability females to choose more competitive (performance related) payment schemes and moving low ability males toward less competitive forms. ${ }^{3}$

The literature based on sports is somewhat larger but provides contrasting results. ${ }^{4}$ Wozniak (2012), using data from lower ranks tennis players (International Tennis Federation), investigates the impact of previous performance on current performance and on the decision to entry in the next competition. He shows that the number of matches won in the current tournament depends positively on the matches won in the last tournament (this holds true both for males and females) while a positive influence of matches won in the before last tournament is found only for males but not for females. In addition, he finds that the probability of entering in a tournament is positively affected by previous performance and this effect is again more persistent for males, although some heterogeneous effects are found according to abilities. In a point-bypoint analysis of some Grand Slam tennis matches, Paserman (2010) finds that women are more likely than men to make errors at crucial phases of the match. In contrast, Gauriot and Page (2014) use a point by point ball tracking data from tennis matches estimating the effect of winning a point on the chance to win the next point and find a positive momentum effect for males but not for females. Banko, Leeds and Leeds (2014) use tennis data to investigate whether women react more negatively to setbacks than men and do not find any difference: from their estimates it emerges that women who lose the first set are not more likely than men to lose the match at the second round or at the third round. Similarly, Jetter and Walker (2015) and Livingstone (2012), using respectively data from tennis and golf, show that the number of past wins positively affects the probability of winning the current match with no gender differences.

While most of these studies consider reactions to outcomes obtained at previous matches, we focus on the interdependence of outcomes within the same match. This choice is motivated by the belief that psychological feelings generate immediate reactions that can be better detected by looking at what happens immediately after an individual experiences success or failure. ${ }^{5}$ Therefore, we analyze the effect that the first set outcome produces on second set players' performance and then on the effect of second set outcome on third set performance.

The paper is organized as follows. In section 2 we describe the data used and present some descriptive statistics. In section 3 we present our main results investigating how first set result affects second set

\footnotetext{
${ }^{3}$ Mobius et al. (2014) investigate how a sample of undergraduate students change their beliefs about their relative performance on an IQ test when they receive feedback and find that women are more conservative that men, reacting significantly less both to negative and positive feedback.

${ }_{4}^{4}$ As regards the evidence on momentum, regardless of gender differences, some works find that previous wins positively affects subsequent performance (Klaassen and Magnus, 2001; Malueg and Yates, 2010), while others do not find any effect (Bar-Eli, Avugos and Raab, 2006).

${ }^{5}$ Paserman (2010) and Gauriot and Page (2014) consider the effect of the outcome of a single point in tennis matches on subsequent performance, but it is likely that losing a point creates only a tiny disadvantage and does not trigger significant psychological reactions in players.
} 
performance. Section 4 is devoted at analyzing how second set result affects performance in the third set. Section 5 concludes.

\section{The Data and the Empirical Strategy}

To investigate the reactions of males and females to previous wins and losses we use data on tennis matches from 2007 to 2014 (available at http://www.tennis-data.co.uk). The database contains results and betting odds from all the tournaments organized by the Association of Tennis Professionals (ATP) and by the Women's Tennis Association (WTA), the main organizing bodies of, respectively, men's and women's professional tennis.

The data contain a wealth of detailed information for each match in each tournament: the names of the respective players, the number of games in each set and the number of sets won by each player, the date of the match, the name of the tournament and the location, the players' entry ranking at the start of the tournament (players are ranked according to their performance in the latest 20 or so tournaments played); betting odds of several leading online gambling companies (Bet365, Bwin, Ladbrokes, Expekt, etc.); the surface (Clay, Grass, Hard, Others), the court (outdoors or indoors), the round of the match, if there has been a walkover or retirement, if the match is best-of-3 or best-of-5.

To win a match in tennis, a player must win two of three sets in a best-of-three match or three of five sets in a best-of-five match. A set in tennis is divided into games and a player must win at least six games to win the set but has to win by two games; if the players are tied at six games apiece, then a special tiebreaking game is played.

We consider only best-of-three matches, representing $87 \%$ of the matches played. ${ }^{6}$ For the eight years considered, we observe 519 tournaments for males and 457 tournaments for females involving 619 men and 605 women. We have information on a total 35,441 matches.

Our analysis is aimed at understanding whether the results of previous sets affect subsequent players' performance and whether this effect is heterogeneous according to gender. Our empirical strategy is quite simple: we firstly analyze the respective outcomes of players in their second set (in terms of games won and lost, but also in the probability of winning the set) in relation to the outcome of the first set. Since we are interested in whether men and women show a different reaction to the outcome of the first set, we regress the outcome of the second set on the outcome of the first set and interact the latter with a gender dummy. Then, we follow the same strategy for the third set and investigate whether the outcome of each player in the third set depends on the outcome of the second set. To control for players' abilities and recent performance, we use both players' professional rankings, betting odds and days of rest.

The variables in the dataset are defined as the outcome of player A with respect to the outcome of player B and for each match we randomly select a player to be A and the opponent to be B.

\footnotetext{
${ }^{6}$ Best-of-five matches are played only in the four tournaments of the Grand Slam (only by males).
} 
Our main dependent variables are Game Difference II set, the number of games won by A minus the games won by B in the first set, and Game Difference III set, defined analogously. We also use as dependent variables the dummy variables Won II set and Won III set, equal to one if A won, respectively, the II set or the III set.

The main explanatory variables are Lost I set, a dummy equal to one if A lost the I set, and Lost II set, defined analogously. To control for players' ability we use the Ranking Difference as the difference between the ranking of A minus the ranking of B in the official rankings: Ranking Difference is therefore positive when $\mathrm{A}$ is playing against a better ranked player and vice-versa. We also consider betting odds: we select the betting odds of four online gambling companies (bet365, bwin, Ladbroke, Expekt) with more observations (the betting odds of some companies are available only for a limited period of time) and build, for each player in each match, the average of betting odds of the four selected companies (Betting Odds A, Betting Odds $B$ ). Then, we use as explanatory variable the Betting Difference as the difference between the Betting Odds A minus the Betting Odds B. Furthermore, on the basis of betting odds, we build the probability of

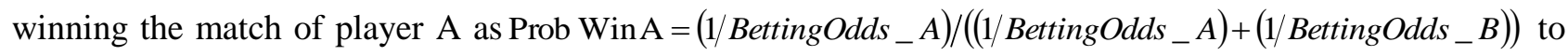
insure that Prob. Win. A ranges between 0 and 1 and to make easily interpretable its effect.

We also build a variable named Rest Difference as the days of rest, after the latest match, enjoyed by player A minus the rest of player B (days of rest are set to 7 if they are greater than 7). Female is a dummy equal to one for females.

In Table 1 are shown some descriptive statistics. About 53\% of the matches in our dataset are played by women. The ranking of players is on average 71, taking values from 1 to 476 . The player losing the first set had a lower probability of winning the match compared to the winner of the set $(0.41$ and 0.59 respectively). About $33 \%$ of players who won the first set also won the second set (34.15\% for females and $32.87 \%$ for males).

\section{Table 1. Descriptive Statistics}

\begin{tabular}{|c|c|c|c|c|c|}
\hline Variable & Obs. & Mean & Std. Dev. & Min & Max \\
\hline Game Difference I set & 35,441 & 0.004 & 3.213 & -6 & 6 \\
\hline Game Difference II set & 35,441 & 0.000 & 3.316 & -6 & 6 \\
\hline Game Difference III set & 11,717 & -0.034 & 3.227 & -6 & 6 \\
\hline Lost I set & 35,441 & 0.500 & 0.500 & 0 & 1 \\
\hline Lost II set & 35438 & 0.499 & .500 & 0 & 1 \\
\hline Female & 35,441 & 0.529 & 0.499 & 0 & 1 \\
\hline Betting Odds A & 35,223 & 2.633 & 2.299 & 1.005 & 50.750 \\
\hline Betting Odds B & 35,223 & 2.646 & 2.330 & 1.003 & 39.000 \\
\hline Betting Odds Diff & 35,223 & -0.013 & 3.826 & -37.995 & 49.748 \\
\hline Prob. Win A & 35,223 & 0.501 & 0.222 & 0.019 & 0.975 \\
\hline Ranking Player A & 35,372 & 71.417 & 75.585 & 1 & 476 \\
\hline Ranking Player B & 35,378 & 71.014 & 75.336 & 1 & 476 \\
\hline Ranking Diff & 35,309 & 0.428 & 99.624 & -475 & 475 \\
\hline Rest Diff & 35,441 & 0.005 & 1.897 & -7 & 7 \\
\hline Round of the match & 35,441 & 3.465 & 2.059 & 1 & 10 \\
\hline Year & 35,439 & 2010.465 & 2.297 & 2007 & 2014 \\
\hline
\end{tabular}

Notes: The data are from Association of Tournament Professionals (ATP) and Women's Tennis Association (WTA) (2007-2014). The variables measuring various outcomes of the match are defined as the outcome of player A minus the outcome of player B. 


\section{Gender Differences in Reaction to a Negative Result at the First Set}

In this Section we analyze how the first set outcome affects players' performance in the second set and whether this effect is differentiated according to gender. We also investigate whether players' responses are heterogeneous according to the magnitudes of the stakes at hand, to the relative ability of each player compared to their opponents and to players' experience.

\subsection{Gender Differences in Reaction to a Negative Result at the First Set}

We estimate a number of models to verify if there are gender differences in the performance of players after having experienced a loss at the first set of a tennis match.

In Table 2 are reported results obtained estimating our model separately for males and females. The dependent variable is Game Difference II Set. In the first two columns, controlling for the ranking difference between the two players, we show that female players losing the first set win 2.38 games less than their opponents winning the first set. On the other hand, male players losing the first set tend to win 1.72 games less than their opponents. It seems that for females the outcome of the first set has a much greater influence on the outcome of the second set: a bad early performance carries over its effects on subsequent results.

In columns (3) and (4) we add as a further control for players' abilities their difference in the betting odds and we also control for the difference in days of rest of the two players, the type of surface, 8 dummies for the round (final; semi-finals; quarter-finals and so on), the year (8) and the month (12). Also in this case, we find that females losing the first set tend to perform much worse in the second set with respect to males losing the first set. Ranking Difference produces the expected effect on the outcome: when it is positive (player A is worse ranked than player B) there is a negative effect on the games gained by player A in the second set. A similar effect is found for Betting Odds Difference.

Table 2. OLS Estimates. Game Difference in the Second Set. Separate Estimates by Gender

\begin{tabular}{|c|c|c|c|c|c|c|}
\hline & $\begin{array}{c}(1) \\
\text { Females }\end{array}$ & $\begin{array}{c}(2) \\
\text { Males }\end{array}$ & $\begin{array}{c}(3) \\
\text { Females }\end{array}$ & $\begin{array}{c}(4) \\
\text { Males }\end{array}$ & $\begin{array}{c}(5) \\
\text { Females }\end{array}$ & $\begin{array}{c}(6) \\
\text { Males }\end{array}$ \\
\hline Lost I set & $\begin{array}{c}-2.380 * * * \\
(0.049)\end{array}$ & $\begin{array}{c}-1.718 * * * \\
(0.046)\end{array}$ & $\begin{array}{c}-1.924 * * * \\
(0.051)\end{array}$ & $\begin{array}{c}-1.372 * * * \\
(0.048)\end{array}$ & $\begin{array}{c}-1.788 * * * \\
(0.052)\end{array}$ & $\begin{array}{c}-1.240 * * * \\
(0.048)\end{array}$ \\
\hline Ranking Diff & $\begin{array}{c}-0.007 * * * \\
(0.000)\end{array}$ & $\begin{array}{c}-0.005 * * * \\
(0.000)\end{array}$ & $\begin{array}{c}-0.002 * * * \\
(0.000)\end{array}$ & $\begin{array}{c}-0.002 * * * \\
(0.000)\end{array}$ & & \\
\hline Betting Odds Diff & & & $\begin{array}{c}-0.251 * * * \\
(0.007)\end{array}$ & $\begin{array}{c}-0.208 * * * \\
(0.008)\end{array}$ & & \\
\hline Prob. Win A & & & & & $\begin{array}{l}5.272 * * * \\
(0.117)\end{array}$ & $\begin{array}{c}4.522 * * * \\
(0.114)\end{array}$ \\
\hline $\begin{array}{l}\text { Controls: Rest; Surfaces; } \\
\text { Round; Year; Month }\end{array}$ & NO & $\mathrm{NO}$ & YES & YES & YES & YES \\
\hline Observations & 18672 & 16634 & 18566 & 16524 & 18606 & 16546 \\
\hline Adjusted R-squared & 0.191 & 0.128 & 0.237 & 0.172 & 0.250 & 0.189 \\
\hline
\end{tabular}

Notes: The Table reports OLS estimates. The dependent variable is Game Difference II Set. Standard errors (reported in parentheses) are corrected for heteroskedasticity. The symbols ***, **,* indicate that coefficients are statistically significant, respectively, at the 1,5 , and 10 percent level. 
In columns (5) and (6), instead of controlling for Ranking Difference, we control for the probability of winning the match by player A. Again, our results do not change qualitatively. Consistently, the probability of winning the match by player A produces a positive effect.

It is also worthwhile to notice that the impact of the probability of winning on the dependent variable is much stronger for females than for males: playing against a competitor that has higher probability of winning of 10 percentage points leads to 0.53 games less for females and 0.45 less for males. This is consistent with the idea that females feel more psychological pressure when they are behind and need to catch up.

In Table 3 we report estimation results obtained considering jointly males and females to test if gender differences are statistically significant. In the first three columns are reported the same specifications of Table 2. In column (1), controlling for Ranking Difference, we show that males losing the first set lose 1.666 games more than the opponent in the second set, while females losing the first set lose $2.442(=-1.666-$ $0.776)$ games more. The interaction term Female $*$ Lost I set is negative and highly significant $(t$-stat $=-12.08)$.

These results hold true in column (2) when we add controls for other players' characteristics (difference in the betting odds and difference in days of rest), for match features (round dummies, surface dummies, year and month dummies). In addition, in column (2) we include an interaction term between Female and the Ranking Difference to take into account that the rankings could convey heterogeneous information about abilities for males and females. We also control for the absolute ranking of player A: in fact, the difference in abilities among two opponents could have different impact if they are, respectively, the first and the eleventh players or if they are 101 and 111, since the difference in abilities should be much larger in the first case. ${ }^{7}$

In column (3) we consider as a measure of differences in abilities among players the probability of winning the match of player A, instead of the Ranking Difference (these two variables are highly correlated). We find again very similar results about gender differences in reaction to a loss in the first set: -1.177 for males and -1.848 for females.

In column (4) we estimate a specification in which we also add among controls an interaction term between the probability of winning the match of player A, Prob. Win A, and the dummy variable Female. The effect of interest remains qualitatively unchanged even if gender differences are smaller in magnitude: males losing the first set lose 1.240 games more than the opponent in the second set, while females losing the first set lose 1.785 (=-1.240-0.545) games more.

In line with what we found when running separate regressions for males and females, in these estimates based on the whole sample we find that the interaction term Prob. Win A* Female is positive and highly statistically significant, implying that, ceteris paribus, the probability of winning has a stronger impact on females' performance compared to males. This could depend on the fact that females suffer more

\footnotetext{
${ }^{7}$ Furthermore, we also experimented adding a square term of the difference in rankings to capture any non-linear impact of ranking difference and we find that results are substantially unchanged (not reported).
} 
than males from the psychological pressure deriving from facing more favorite opponents (the same results are found when we consider the interaction term Ranking Difference*Female).

Finally, in columns (5) and (6) we add among controls player and tournament fixed effects respectively. When controlling for player fixed effect we find that male players losing the first set lose about 1.235 games more than their opponent in the second set, whereas females losing the first set tend to lose about 1.768 games more. The difference is again highly statistically significant $(t$-stat: -7.43$)$. Similar results are found in column (6) where we control for tournament fixed effects.

Notice that in some specifications the coefficient on Female turns out to be different from zero since some variables as Ranking Differences take different mean values for males and females but the dependent variable is zero for both categories.

Table 3. OLS estimates. Game Difference in the Second Set. Whole Sample

\begin{tabular}{|c|c|c|c|c|c|c|}
\hline & $(1)$ & $(2)$ & $(3)$ & $(4)$ & $(5)$ & $(6)$ \\
\hline Lost I set & $\begin{array}{c}-1.666^{* * *} \\
(0.046)\end{array}$ & $\begin{array}{c}-1.335^{* * *} \\
(0.046)\end{array}$ & $\begin{array}{c}-1.177 * * * \\
(0.046)\end{array}$ & $\begin{array}{c}-1.240 * * * \\
(0.048)\end{array}$ & $\begin{array}{c}-1.235^{* * *} \\
(0.049)\end{array}$ & $\begin{array}{c}-1.239 * * * \\
(0.048)\end{array}$ \\
\hline Female & $\begin{array}{c}0.410 * * * \\
(0.045)\end{array}$ & $\begin{array}{c}0.303 * * * \\
(0.046)\end{array}$ & $\begin{array}{c}0.321 * * * \\
(0.045)\end{array}$ & $\begin{array}{l}-0.119 \\
(0.102)\end{array}$ & & $\begin{array}{l}-0.122 \\
(0.108)\end{array}$ \\
\hline Female*Lost I set & $\begin{array}{l}-0.776 * * * \\
(0.064)\end{array}$ & $\begin{array}{c}-0.625 * * * \\
(0.066)\end{array}$ & $\begin{array}{c}-0.671 * * * \\
(0.062)\end{array}$ & $\begin{array}{c}-0.545^{* * *} \\
(0.070)\end{array}$ & $\begin{array}{c}-0.534 * * * \\
(0.072)\end{array}$ & $\begin{array}{c}-0.548 * * * \\
(0.070)\end{array}$ \\
\hline Ranking Diff & $\begin{array}{c}-0.006 * * * \\
(0.000)\end{array}$ & $\begin{array}{c}-0.001 * * * \\
(0.000)\end{array}$ & & & & \\
\hline Female*Ranking Diff & & $\begin{array}{c}-0.001 * * * \\
(0.000)\end{array}$ & & & & \\
\hline Betting Odds Diff & & $\begin{array}{c}-0.230 * * * \\
(0.005)\end{array}$ & & & & \\
\hline Prob. Win A & & & $\begin{array}{c}4.933 * * * \\
(0.082)\end{array}$ & $\begin{array}{c}4.525 * * * \\
(0.110)\end{array}$ & $\begin{array}{c}4.387 * * * \\
(0.130)\end{array}$ & $\begin{array}{c}4.520 * * * \\
(0.110)\end{array}$ \\
\hline Female*(Prob. Win A) & & & & $\begin{array}{l}0.752 * * * \\
(0.148)\end{array}$ & $\begin{array}{l}0.749 * * * \\
(0.177)\end{array}$ & $\begin{array}{c}0.745^{* * * *} \\
(0.149)\end{array}$ \\
\hline $\begin{array}{l}\text { Controls: Rest Diff; Ranking A; } \\
\text { Surfaces; Round; Year; Month }\end{array}$ & $\mathrm{NO}$ & YES & YES & YES & YES & YES \\
\hline Tournament fixed effects & NO & NO & NO & NO & NO & YES \\
\hline Player fixed effects & NO & NO & NO & NO & YES & $\mathrm{NO}$ \\
\hline Observations & 35306 & 35090 & 35152 & 35152 & 35152 & 35152 \\
\hline Adjusted R-squared & 0.164 & 0.210 & 0.225 & 0.225 & 0.225 & 0.225 \\
\hline
\end{tabular}

Notes: The Table reports OLS estimates. The dependent variable is Game Difference II Set. Standard errors (reported in parentheses) are corrected for heteroskedasticity. The symbols ***, **,* indicate that coefficients are statistically significant, respectively, at the 1,5 , and 10 percent level.

We have also experimented by using as main explanatory variable Game Difference I Set (in place of the dummy Lost I Set). We find that for females that obtain a negative game difference in the first set, there is a stronger negative effect on the Game Difference in the second set. For instance when estimating specification 5 of Table 3 we find that one more game lost in the first set is associated with a reduction of 0.21 in the number of games won in the second set for males, while for females it reduces of 0.27 the games won (results not reported). Similar estimates are obtained in other specifications.

We find qualitatively very similar results also when using as a dependent variable the probability of winning the second set on the basis of the outcome of the first set (see Appendix of the paper). 
All in all, our estimation results highlight a quite strong gender difference in players' response to the first set result, that can be due to gender differences in the ability to handle the emotional feelings following the feedback of bad or good performance and the uneasiness of falling behind and the necessity of catching up. Our result is in line with the results of Apesteguia and Palacios-Huerta (2010) who find that the main determinant of success of players in penalty kicking is whether a team is lagging in score, because this state puts considerable psychological pressure on the players.

However, our results could be related to unobserved ability. Even if we control for players' ability (using rankings, betting odds, players' probability of winning) it could still happen that one of the players turned out to be stronger the day of the match. Then, the negative effect that losing the previous set produces on the following set performance could be due to differences in ability: the player who won the previous set is characterized by higher ability and, as a consequence, he/she also tend to perform better the next set. Even if there are no reasons to believe that unobserved ability has a differentiate relevance according to gender we cannot exclude it. Therefore, to account for this potential bias we have run some robustness checks.

Firstly, we consider only those matches in which the previous set was "close". In tennis a set is divided in games and to win a set a player must win six games with a two-game advantage. If the players are tied at six games in any set, they proceed to a tie-breaking game. Following Malueg and Yates (2010), we define "close" to mean that at some point, the set was tied at five games apiece. This implies that the winner either won seven games to five or won the tie-breaking game after the set was tied at six games apiece.

When we consider only matches in which the first set was close we end up with a sample of 8,213 matches. Using this sub-sample we replicate specifications (4), (5) and (6) reported in Table 3. As shown in columns (1), (2) and (3) of Table 4 our main results remain qualitatively unchanged. Also considering this sub-sample we find (column 1) that male players losing the first set gain about 1.061 games less than their opponent in the second set, whereas females losing the first set tend to lose about 1.465 games more. The difference is again highly statistically significant and the magnitude of the effect is slightly smaller compared to that found considering the whole sample. Very similar results are found when we control for player fixed effects (column 2) and for tournament fixed effects (column 3).

As a second robustness check we have restricted our sample to those matches in which, according to betting odds, the players' probability of winning the match were very similar (Prob. Win A in the range of $0.40-0.60)$. We are left with a subsample of 9,525 matches. In the last three columns of Table 4 , we replicate the specifications used in the three first columns. Also in this case, we obtain qualitatively the same results discussed above. In all specifications, male players losing the first set win about 1.4 games less than their opponent, while for females this effect is larger of about 0.4 games.

Table 4. OLS estimates. Close Matches and Matches with Similar Probability of Winning

\begin{tabular}{lcccccc}
\hline & \multicolumn{3}{c}{ Close } & \multicolumn{3}{c}{ Similar } \\
Probability
\end{tabular}




\begin{tabular}{|c|c|c|c|c|c|c|}
\hline Female & $\begin{array}{c}0.042 \\
(0.204)\end{array}$ & & $\begin{array}{c}0.020 \\
(0.220)\end{array}$ & $\begin{array}{c}0.373 \\
(0.533)\end{array}$ & & $\begin{array}{c}0.396 \\
(0.540)\end{array}$ \\
\hline Female*Lost I set & $\begin{array}{c}-0.404 * * * \\
(0.139)\end{array}$ & $\begin{array}{c}-0.348^{* *} \\
(0.150)\end{array}$ & $\begin{array}{c}-0.418 * * * \\
(0.140)\end{array}$ & $\begin{array}{c}-0.389 * * * \\
(0.127)\end{array}$ & $\begin{array}{c}-0.333 * * \\
(0.134)\end{array}$ & $\begin{array}{c}-0.395 * * * \\
(0.128)\end{array}$ \\
\hline Prob. Win A & $\begin{array}{c}4.277 * * * \\
(0.216)\end{array}$ & $\begin{array}{c}4.204 * * * \\
(0.264)\end{array}$ & $\begin{array}{c}4.317 * * * \\
(0.219)\end{array}$ & $\begin{array}{c}4.567 * * * \\
(0.698)\end{array}$ & $\begin{array}{c}4.297 * * * \\
(0.745)\end{array}$ & $\begin{array}{c}4.658 * * * \\
(0.701)\end{array}$ \\
\hline Female*(Prob. Win A) & $\begin{array}{c}0.143 \\
(0.318)\end{array}$ & $\begin{array}{c}0.061 \\
(0.394)\end{array}$ & $\begin{array}{c}0.093 \\
(0.321)\end{array}$ & $\begin{array}{l}-0.415 \\
(1.037)\end{array}$ & $\begin{array}{l}-0.482 \\
(1.107)\end{array}$ & $\begin{array}{l}-0.471 \\
(1.042)\end{array}$ \\
\hline $\begin{array}{l}\text { Controls: Rest Diff; Ranking A; } \\
\text { Surfaces; Round; Year; Month }\end{array}$ & YES & YES & YES & YES & YES & YES \\
\hline Tournament fixed effects & NO & NO & YES & $\mathrm{NO}$ & NO & YES \\
\hline Player fixed effects & NO & YES & NO & NO & YES & NO \\
\hline Observations & 8213 & 8213 & 8213 & 9525 & 9525 & 9525 \\
\hline Adjusted R-squared & 0.140 & 0.141 & 0.144 & 0.072 & 0.072 & 0.072 \\
\hline
\end{tabular}

Notes: The Table reports OLS estimates. The dependent variable is Game Difference II Set. Standard errors (reported in parentheses) are corrected for heteroskedasticity. The symbols ***, **, * indicate that coefficients are statistically significant, respectively, at the 1,5 , and 10 percent level.

\subsection{Gender differences according to match relevance, players' ability and experience}

In this sub-section we investigate whether players' response to previous set results is heterogeneous according to the magnitudes of the stakes at hand, to players' relative ability and to players experience.

We firstly investigate whether the gender differences in response to the negative result at the first set changes when the importance of the match is higher (on the role of the importance of success see the discussion in Dohmen, 2008). At this aim we have built a variable Final taking the value of 1 when the round of the match is a final and three interaction terms. The first interaction term Final* Lost I set is aimed at catching any difference in response to having lost the first set for male players when the tournament has reached its final match. The second interaction term Final*Female takes into account any difference in female behavior in the last round of the tournament, while the third interaction term Final*Lost I set $^{*}$ Female shows whether female players, having lost the first set, react differently during a final compared to how they react in matches at an earlier stage of the tournament.

Estimates are reported in Table 5 in which we replicate the specifications of Table 4. Losing the first set in a final match produces a negative effect on the probability of winning the second set, however, for males during a final match this effect is much smaller compared to that they experience in less challenging matches - in the first specification it amounts to $0.475(=-1.263+0788)$, that is, less than half of the effect experienced in the other matches $(-1.263)$. On the contrary, female players who have reached a final match are more negatively affected by having lost the first set compared to what happens at earlier stages of the tournament. The interaction term Final*Lost I set*Female is negative, statistically significant and quite large in magnitude (-0.982). During a final match a female player who has lost the first set wins 2.762 games less $(=-1.263-0.517-0.982)$ than her opponent in the second set.

We have also experimented considering among high stakes matches semi-finals in addition to finals and we find very similar results. 
This result is consistent with the idea that women are more sensitive - and show more stronger emotional reactions - to situations that generate pressure, since during a final match the pressure deriving from having lost the first set is amplified by the importance of the match.

Table 5. OLS estimates. Differential Responses in the Final Match

\begin{tabular}{|c|c|c|c|}
\hline & $(1)$ & $(2)$ & (3) \\
\hline \multirow[t]{2}{*}{ Lost I set } & $-1.263 * * *$ & $-1.257 * * *$ & $-1.261 * * *$ \\
\hline & $(0.049)$ & $(0.050)$ & $(0.049)$ \\
\hline \multirow[t]{2}{*}{ Female } & -0.129 & & -0.133 \\
\hline & $(0.102)$ & & $(0.109)$ \\
\hline \multirow[t]{2}{*}{ Female*Lost I set } & $-0.517 * * *$ & $-0.508 * * *$ & $-0.521 * * *$ \\
\hline & $(0.071)$ & $(0.073)$ & $(0.071)$ \\
\hline \multirow[t]{2}{*}{ Final } & $-0.462 * *$ & $-0.520 * * *$ & $-0.485 * * *$ \\
\hline & $(0.181)$ & $(0.186)$ & $(0.181)$ \\
\hline \multirow[t]{2}{*}{ Final*Female } & 0.360 & 0.297 & 0.381 \\
\hline & $(0.284)$ & $(0.290)$ & $(0.284)$ \\
\hline \multirow[t]{2}{*}{ Final*Lost I set } & $0.788 * * *$ & $0.741 * * *$ & $0.787 * * *$ \\
\hline & $(0.251)$ & $(0.256)$ & $(0.251)$ \\
\hline \multirow[t]{2}{*}{ Final*Lost I set*Female } & $-0.982 * *$ & $-0.905 * *$ & $-0.975^{* *}$ \\
\hline & $(0.395)$ & $(0.401)$ & $(0.396)$ \\
\hline \multirow[t]{2}{*}{ Prob. Win A } & $4.525 * * *$ & $4.396 * * *$ & $4.520 * * *$ \\
\hline & $(0.110)$ & $(0.130)$ & $(0.110)$ \\
\hline \multirow[t]{2}{*}{ Female*(Prob. Win A) } & $0.754 * * *$ & $0.737 * * *$ & $0.746 * * *$ \\
\hline & $(0.148)$ & $(0.178)$ & $(0.149)$ \\
\hline $\begin{array}{l}\text { Controls: Rest Diff; Ranking A; } \\
\text { Surfaces; Round; Year; Month }\end{array}$ & YES & YES & YES \\
\hline Tournament fixed effects & $\mathrm{NO}$ & NO & YES \\
\hline Player fixed effects & NO & YES & NO \\
\hline Observations & 35152 & 35152 & 35152 \\
\hline Adjusted R-squared & 0.226 & 0.225 & 0.225 \\
\hline
\end{tabular}

Notes: The Table reports OLS estimates. The dependent variable is Game Difference II Set. Standard errors (reported in parentheses) are corrected for heteroskedasticity. The symbols ***, **, * indicate that coefficients are statistically significant, respectively, at the 1,5 , and 10 percent level.

Pressure can also derive from facing higher ranked opponents who have a much higher probability of winning the match. As discussed above the interaction term Female* Prob. Win A is always positive and quite relevant in magnitude, implying that the ex-ante difference in probability between players are much more important for females.

It could be that favorite players (those facing lower ranked opponents) react differently when losing the first set compared to underdog players. To investigate this aspect we run separate regressions for players who had a very high probability of winning the match (higher than $67 \%$, corresponding to the $75^{\text {th }}$ percentile), for players with a very low probability of winning (lower than $32 \%$, the $25^{\text {th }}$ percentile) and for players in between. Results are shown in the first three columns of Table 6. The gender difference in response to first set results does not seem related to the pressure deriving from facing particularly challenging opponents: the magnitude of the coefficient of interest is very similar in the three sub-samples.

Players' ability to respond to pressure can be acquired through experience and practice. To better investigate this issues we analyze the gender gap in response to first set results in relation to players' experience. Unfortunately, data at hand do not provide information neither on players' age nor on their 
seniority as professional players. As a consequence, we use as a proxy of each player's experience the number of matches he/she has played in all the tournaments during the period 2007-2014 included in our dataset. Our variable takes values in the range 1-271. Then, we consider separately matches disputed by players belonging to the first quartile of the experience distribution (less than 50 matches), matches in the second and third quartile (between 50 matches and 156) and matches in the fourth quartile. As shown in columns 4, 5 and 6 of Table 6 , it seems that male reaction to having lost the first tend to slightly improve with experience, while female reaction tend to remain unchanged (ranging from -1.7 to -1.8). However, these differences are not statistically significant, implying that the ability to deal with the emotions deriving from failure and success does not change much with experience.

Table 6. OLS estimates. Heterogeneous Effects according to Probability of Winning and Experience

\begin{tabular}{|c|c|c|c|c|c|c|}
\hline & (1) & $(2)$ & (3) & (4) & $(5)$ & (6) \\
\hline & \multicolumn{3}{|c|}{ Prob. Win A } & \multicolumn{3}{|c|}{ Experience } \\
\hline & $>=0.67$ & $\begin{array}{l}>0.32 \& \\
<0.67\end{array}$ & $<=0.32$ & $<=25^{\text {th }}$ & $\begin{array}{c}>25^{\text {th }} \& \\
<75^{\text {th }}\end{array}$ & $>=75^{\text {th }}$ \\
\hline Lost I set & $\begin{array}{c}-1.248 * * * \\
(0.102)\end{array}$ & $\begin{array}{c}-1.301 * * * \\
(0.064)\end{array}$ & $\begin{array}{c}-1.052 * * * \\
(0.105)\end{array}$ & $\begin{array}{c}-1.319 * * * \\
(0.095)\end{array}$ & $\begin{array}{c}-1.227 * * * \\
(0.065)\end{array}$ & $\begin{array}{c}-1.128 * * * \\
(0.108)\end{array}$ \\
\hline Female & $\begin{array}{l}-0.963 \\
(0.632)\end{array}$ & $\begin{array}{c}0.127 \\
(0.249)\end{array}$ & $\begin{array}{c}-0.413^{*} \\
(0.244)\end{array}$ & $\begin{array}{l}-0.138 \\
(0.217)\end{array}$ & $\begin{array}{c}-0.034 \\
(0.156)\end{array}$ & $\begin{array}{c}-0.494^{*} \\
(0.253)\end{array}$ \\
\hline Female*Lost I set & $\begin{array}{c}-0.579 * * * \\
(0.147)\end{array}$ & $\begin{array}{c}-0.523 * * * \\
(0.095)\end{array}$ & $\begin{array}{c}-0.521 * * * \\
(0.153)\end{array}$ & $\begin{array}{c}-0.427 * * * \\
(0.143)\end{array}$ & $\begin{array}{c}-0.576^{* * * *} \\
(0.099)\end{array}$ & $\begin{array}{c}-0.649 * * * \\
(0.145)\end{array}$ \\
\hline Prob. Win A & $\begin{array}{l}5.322 * * * \\
(0.576)\end{array}$ & $\begin{array}{c}4.464 * * * \\
(0.311)\end{array}$ & $\begin{array}{l}5.645^{* * * *} \\
(0.580)\end{array}$ & $\begin{array}{l}4.708 * * * \\
(0.253)\end{array}$ & $\begin{array}{c}4.584 * * * \\
(0.162)\end{array}$ & $\begin{array}{l}3.729 * * * \\
(0.253)\end{array}$ \\
\hline Female*(Prob. Win A) & $\begin{array}{l}1.921 * * \\
(0.781)\end{array}$ & $\begin{array}{c}0.167 \\
(0.452)\end{array}$ & $\begin{array}{l}1.994 * * \\
(0.815)\end{array}$ & $\begin{array}{l}1.007 * * * \\
(0.346)\end{array}$ & $\begin{array}{l}0.396 * \\
(0.227)\end{array}$ & $\begin{array}{l}1.429 * * * \\
(0.323)\end{array}$ \\
\hline $\begin{array}{l}\text { Controls: Rest Diff; Ranking A; } \\
\text { Surfaces; Round; Year; Month }\end{array}$ & YES & YES & YES & YES & YES & YES \\
\hline Tournament fixed effects & YES & YES & YES & $\mathrm{NO}$ & YES & YES \\
\hline Player fixed effects & NO & NO & NO & NO & NO & YES \\
\hline Observations & 9192 & 17377 & 8583 & 8897 & 17288 & 8967 \\
\hline Adjusted R-squared & 0.103 & 0.093 & 0.086 & 0.200 & 0.196 & 0.208 \\
\hline
\end{tabular}

Notes: The Table reports OLS estimates. The dependent variable is Game Difference II Set. Standard errors (reported in parentheses) are corrected for heteroskedasticity. The symbols $* * *, * *, *$ indicate that coefficients are statistically significant, respectively, at the 1,5 , and 10 percent level.

\section{Gender Differences in Reaction to a Balanced Outcome}

When the match goes to a third set players have both won a set. With respect to the situation at the beginning of the second set, in the third set players are in a symmetric condition and have received two contrasting feedbacks on their performance, one positive and one negative. Even if players are in a symmetric conditions, the psychological emotions deriving from winning and losing might still be relevant: the loser of the second set might experience some immediate feelings of stress and discouragement, while the winner might feel excitement.

To investigate whether this is the case and whether these reactions differ according to gender we have estimated an OLS model using as dependent variable Game Difference III set and Lost II set as main explanatory variable. 
We estimate the same specifications of Table 3 and we report results in Table 7. Notice that the number of observations is much smaller $(11,690)$, since only a third of the matches ends to the third set. In all specifications players losing the second set gain about 0.30 games less than their opponent in the third set. Although we still find a "momentum effect" of the second set on third set performance, the magnitude of the effect is much smaller compared to that produced by Lost I set on second set performance, probably because, as discussed above, when the contest goes to a third set players face symmetric conditions and have received mixed feedbacks: as a consequence, the behavioral reaction to having lost the second set is less pronounced.

The interaction term Female*(Lost II set) is negative but far from being statistically significant implying that males and females react similarly to the second set outcome. Probably, females in a balanced condition feel less pressured (in comparison to the second set unbalanced situation) and their performance in the third set is little affected.

The same qualitative results are found when we consider as main explanatory variable Difference in Games II set (not reported) and when we consider as dependent variable the probability of winning the third set (see Appendix).

Table 7. OLS estimates. Game Difference in the Third Set. Whole Sample.

\begin{tabular}{|c|c|c|c|c|c|c|}
\hline & $(1)$ & $(2)$ & (3) & $(4)$ & $(5)$ & $(6)$ \\
\hline Lost II set & $\begin{array}{c}-0.318 * * * \\
(0.080)\end{array}$ & $\begin{array}{c}-0.321 * * * \\
(0.077)\end{array}$ & $\begin{array}{c}-0.298 * * * \\
(0.077)\end{array}$ & $\begin{array}{c}-0.297 * * * \\
(0.077)\end{array}$ & $\begin{array}{c}-0.260 * * * \\
(0.081)\end{array}$ & $\begin{array}{c}-0.291 * * * \\
(0.077)\end{array}$ \\
\hline Female & $\begin{array}{c}0.132 \\
(0.082)\end{array}$ & $\begin{array}{l}0.140^{*} \\
(0.082)\end{array}$ & $\begin{array}{c}0.134 \\
(0.082)\end{array}$ & $\begin{array}{c}0.214 \\
(0.159)\end{array}$ & & $\begin{array}{c}0.204 \\
(0.174)\end{array}$ \\
\hline Female* Lost II set & $\begin{array}{l}-0.061 \\
(0.117)\end{array}$ & $\begin{array}{l}-0.069 \\
(0.114)\end{array}$ & $\begin{array}{c}-0.075 \\
(0.113)\end{array}$ & $\begin{array}{l}-0.076 \\
(0.113)\end{array}$ & $\begin{array}{l}-0.069 \\
(0.119)\end{array}$ & $\begin{array}{l}-0.071 \\
(0.114)\end{array}$ \\
\hline Ranking Diff & $\begin{array}{c}-0.007 * * * \\
(0.000)\end{array}$ & $\begin{array}{c}-0.002 * * * \\
(0.001)\end{array}$ & & & & \\
\hline Female*Ranking Diff & & $\begin{array}{l}-0.001 \\
(0.001)\end{array}$ & & & & \\
\hline Betting Odds Diff & & $\begin{array}{c}-0.297 * * * \\
(0.013)\end{array}$ & & & & \\
\hline Prob. Win A & & & $\begin{array}{l}5.079 * * * \\
(0.149)\end{array}$ & $\begin{array}{l}5.162 * * * \\
(0.193)\end{array}$ & $\begin{array}{l}4.862 * * * \\
(0.235)\end{array}$ & $\begin{array}{c}5.149 * * * \\
(0.195)\end{array}$ \\
\hline Female*(Prob. Win A) & & & & $\begin{array}{c}-0.161 \\
(0.270)\end{array}$ & $\begin{array}{c}0.081 \\
(0.327) \\
\end{array}$ & $\begin{array}{l}-0.170 \\
(0.272)\end{array}$ \\
\hline $\begin{array}{l}\text { Controls: Rest Diff; Ranking A; } \\
\text { Surfaces; Round; Year; Month }\end{array}$ & $\mathrm{NO}$ & $\mathrm{NO}$ & YES & YES & YES & YES \\
\hline Tournament fixed effects & NO & NO & $\mathrm{NO}$ & NO & NO & YES \\
\hline Player fixed effects & NO & NO & NO & NO & YES & NO \\
\hline Observations & 11690 & 11621 & 11629 & 11629 & 11629 & 11629 \\
\hline Adjusted R-squared & 0.040 & 0.092 & 0.102 & 0.102 & 0.108 & 0.102 \\
\hline
\end{tabular}

Notes: The Table reports OLS estimates. The dependent variable is Game Difference III Set. Standard errors (reported in parentheses) are corrected for heteroskedasticity. The symbols ***,**,* indicate that coefficients are statistically significant, respectively, at the 1,5 , and 10 percent level.

In Table 8 we focus on close matches, that is, matches for which the second set ended in 7-5, 5-7 or with a tie-break game (columns 1,2 and 3) and on matches in which players' had similar probability of winning, ranging from $40 \%$ to $60 \%$ (columns 4,5 and 6). In both cases, we find that losing the second set 
leads to a negative effect on players' performance at the third set but there is not any statistically significant difference between males and females.

Thus, our evidence suggests the existence of a "momentum effect" also in the third set, although with a much lower magnitude with respect to the second set. More importantly, males and females show similar reactions when they find themselves in a balanced situation and receive one positive and one negative feedback from their previous performance. 


\begin{tabular}{|c|c|c|c|c|c|c|}
\hline & \multicolumn{3}{|c|}{ Close Matches } & \multicolumn{3}{|c|}{$\begin{array}{c}\text { Similar } \\
\text { probability }\end{array}$} \\
\hline & (1) & (2) & (3) & (4) & (5) & (6) \\
\hline Lost II set & $\begin{array}{c}-0.289 * * \\
(0.141)\end{array}$ & $\begin{array}{c}-0.216 \\
(0.163)\end{array}$ & $\begin{array}{c}-0.287 * * \\
(0.145)\end{array}$ & $\begin{array}{c}-0.648 * * * \\
(0.144)\end{array}$ & $\begin{array}{c}-0.503 * * * \\
(0.161)\end{array}$ & $\begin{array}{c}-0.674 * * * \\
(0.147)\end{array}$ \\
\hline Female & $\begin{array}{c}0.382 \\
(0.311)\end{array}$ & & $\begin{array}{c}0.281 \\
(0.349)\end{array}$ & $\begin{array}{l}-0.809 \\
(0.879)\end{array}$ & & $\begin{array}{l}-0.931 \\
(0.905)\end{array}$ \\
\hline Female*Lost II set & $\begin{array}{l}-0.069 \\
(0.226)\end{array}$ & $\begin{array}{l}-0.044 \\
(0.260)\end{array}$ & $\begin{array}{l}-0.103 \\
(0.231)\end{array}$ & $\begin{array}{l}0.407 * \\
(0.212)\end{array}$ & $\begin{array}{c}0.354 \\
(0.236)\end{array}$ & $\begin{array}{l}0.390 * \\
(0.217)\end{array}$ \\
\hline Prob. Win A & $\begin{array}{c}5.195 * * * \\
(0.374)\end{array}$ & $\begin{array}{c}4.857 * * * \\
(0.482)\end{array}$ & $\begin{array}{c}5.087 * * * \\
(0.382)\end{array}$ & $\begin{array}{c}3.037 * * * \\
(1.172)\end{array}$ & $\begin{array}{c}2.749 * * \\
(1.330)\end{array}$ & $\begin{array}{c}3.065 * * \\
(1.195)\end{array}$ \\
\hline Female*(Prob. Win A) & $\begin{array}{c}-0.648 \\
(0.550)\end{array}$ & $\begin{array}{l}-0.531 \\
(0.737)\end{array}$ & $\begin{array}{l}-0.510 \\
(0.568)\end{array}$ & $\begin{array}{c}1.494 \\
(1.727)\end{array}$ & $\begin{array}{c}1.426 \\
(1.929)\end{array}$ & $\begin{array}{c}1.858 \\
(1.762)\end{array}$ \\
\hline $\begin{array}{l}\text { Controls: Rest Diff; Ranking A; } \\
\text { Surfaces; Round; Year; Month }\end{array}$ & YES & YES & YES & YES & YES & YES \\
\hline Tournament fixed effects & NO & NO & YES & NO & NO & YES \\
\hline Player fixed effects & NO & YES & NO & NO & YES & NO \\
\hline Observations & 3106 & 3106 & 3106 & 3600 & 3600 & 3600 \\
\hline Adjusted R-squared & 0.090 & 0.089 & 0.092 & 0.008 & 0.021 & 0.005 \\
\hline
\end{tabular}

Notes: The Table reports OLS estimates. The dependent variable is Game Difference II Set. Standard errors (reported in parentheses) are corrected for heteroskedasticity. The symbols $* * *, * *, *$ indicate that coefficients are statistically significant, respectively, at the 1,5 , and 10 percent level.

\section{Concluding Remarks}

Gender gaps are particularly relevant at the top of the organizational hierarchies suggesting that a relevant part of gender inequalities arises in competitive settings such as promotion tournaments. Since promotion systems have typically the structure of sequential tournaments the gender gaps might be fostered by the different psychological reactions of men and women to success and failure experienced at the different stages of a contest.

To investigate this issue we have used a large dataset from men's and women's professional tennis tournaments. Tennis matches are particularly well suited to study whether males and females behave differently in dynamic contests since the outcome is determined in separate stages. Men and women might experience different psychological reactions to on-going outcomes, for instance because women tend to interpret a negative result as an indicator of their self-worth rather than an episodic event, with adverse consequences on their self-esteem, or because females tend to choke under the pressure of lagging behind.

We have found that women tend to experience a stronger discouragement effect than men when losing the first set: while male players losing the first set lose about 1.2 games more than their opponent in the second set, females losing the first set tend to lose about 1.8 games more. On the other hand, we do not found gender differences in response to second set results: both male and female players who won the second set are equally more likely to win also the third set.

This evidence might depend on the fact that losing the first set creates an unbalanced situation among players. For the player falling behind there is a high risk of failure and thus a strong psychological pressure to succeed in the second set and women might be less capable to deal with emotions deriving from 
the need of catching up. In addition, the negative outcome of the first set represents a feedback that women might handle with more difficulties.

In contrast, in those situations in which women feel in a balanced condition with respect to their opponent and in which there is not only negative feedback - as in the third set of a tennis match - the psychological pressure is less strong and women are as good as men to handle it.

The idea that females react differently from males especially in those situations characterized by a high level of pressure is also supported by the heterogeneous effect we have found in relation to the relevance of the match. Our results show indeed that when stakes become larger, such as in finals, the negative effect of losing the first set on second set performance becomes smaller for males but it increases in magnitude for females.

Our results are robust to the inclusion of many controls such as players' ranking, betting odds, tournament and players fixed effect. They also hold when in order to better take into account players' ability we restrict our analysis to those matches in which the previous set was close and when we consider only the matches involving players with very similar probability of winning.

Our findings can explain gender differences arising in a variety of situations in which subjects compete sequentially and receive feedback on their interim performance - competitions to land a good job, competitions for promotion in firms and public organizations, political elections, sports competitions, and so on.

\section{References}

Apesteguia, J., and I. Palacios-Huerta (2010), "Psychological Pressure in Competitive Environments: Evidence from a Randomized Natural Experiment", American Economic Review, 100, 2548-2564.

Azmat, G., and Petrongolo, B. (2014). "Gender and the labor market: What have we learned from field and lab experiments?", Labour Economics, 30, 32-40.

Banko L., Leeds E., Leeds M. (2014), Gender Differences in Response to Setbacks: Evidence from Professional Tennis, Department of Economics DETU Working Paper No.02.

Bar-Eli M., Avugos S., Raab M. (2006), Twenty years of "hot hand" research: Review and critique, Psychology of Sport and Exercise, 7(6), pp. 525-553.

Baumeister, R. F. (1985). Choking under pressure: self-consciousness and paradoxical effects of incentives on skillful performance. Journal of Personality and Social Psychology. 46, 610-620.

Bertrand, M., (2011), New Perspectives on Gender, Handbook of Labor Economics, vol. 4b, Amsterdam: North-Holland.

Brody, L., 1993. On understanding gender differences in the expression of emotion. In: Ablon, Steven L., Brown, Daniel, Khantzian, Edward J., Mack, John E. (Eds.), Human Feelings: Explorations in Affect Development and Meaning. Analytic Press, Hillsdale, NJ, pp. 87-121.

Buser T. (2014), The Impact of Losing in a Competition on the Willingness to Seek Further Challenges, CESifo Working Paper Series No. 4904.

Croson, R., and U. Gneezy, (2009), Gender Differences in Preferences, Journal of Economic Literature, 47 (2), pp. 448-74.

Dohmen, T. (2008), "Do professionals choke under pressure?", Journal of Economic Behavior \& Organization, 65(3), 636-653.

Dweck C. (2000), Self-theories: Their role in motivation, personality, and development, Psychology Press.

Fehr-Duda, H., de Gennaro, M., Schubert, R., 2006. Gender, financial risk, and probability weights. Theory and Decision 60, 283-313. 
Feri, F., Innocenti, A., and Pin, P. (2013). Is there psychological pressure in competitive environments?. Journal of Economic Psychology, 39, 249-256.

Fu Q., Ke C., Tan, F. (2013), Success breeds success or pride goes before a fall. Teams and Individuals in Best-of-Three Contests, Max Planck Institute for Tax Law and Public Finance, Working Paper n. 06.

Fujita, F., Diener E., Sandvik E. (1991), Gender differences in negative affect and well-being: The case for emotional intensity, Journal of Personality and Social Psychology, 61(3), 427-434.

Gauriot, R., and Page, L. (2014), "Does success breed success? A quasi-experiment on strategic momentum in dynamic contests", (No. 028). QUT Business School.

Giampaolo F. and J. Levey (2013), Championship Tennis,

Gill, D. and Prowse V. (2014), Gender Differences and Dynamics in Competition: The Role of Luck, Quantitative Economics, forthcoming.

Grossman, M, and Wood W. (1993), Sex differences in intensity of emotional experience: A social role interpretation, Journal of Personality and Social Psychology, 65(5), pp. 1010-1022.

Jetter, M. and Walker J. (2015), Game, Set, and Match: Do Women and Men Perform Differently in Competitive Situations?, Journal of Economic Behavior \& Organization, 119, 96-108.

Johnson, M. and Helgeson, V. S. (2002). Sex differences in response to evaluative feedback: A field study, Psychology of Women Quarterly, 26(3), pp. 242-251.

Klaassen F. and Magnus J. (2001), Are Points in Tennis Independent and Identically Distributed? Evidence From a Dynamic Binary Panel Data Model, Journal of the American Statistical Association, 96(545), pp. 500-509.

Kocher, M., Lenz, M., and Sutter, M. (2012), "Psychological pressure in competitive environments: New evidence from randomized natural experiments", Management Science, 58,8 1585-1591.

Livingston J. (2012), The hot hand and the cold hand in professional golf, Journal of Economic Behavior \& Organization, 81(1), pp. 172-184.

Lundgren, D.C., and D.J. Rudawsky, (1998), Female and male college students' responses to negative feedback from parents and peers, Sex Roles, 39 (5-6), pp. 409-429.

Mago S., R. Sheremeta, A. Yates (2013), Best-of-three contest experiments: Strategic versus psychological momentum, International Journal of Industrial Organization, 31(3), pp. 287-296.

Malueg D. and Yates A. (2010), Testing contest theory: evidence from best-of-three tennis matches, Review of Economics and Statistics, 92(3), pp. 689-692.

McPhee J. (1969), Levels of the Game, Macmillan.

Mobius M., Niederle M, Niehaus P, Rosenblat T. (2011), Self-confidence management: theory and experimental evidence. NBER working paper.

Niederle, M., and Vesterlund, L. (2011). Gender and competition. Annu. Rev. Econ., 3(1), 601-630.

Paserman D. (2010), Gender differences in performance in competitive environments: evidence from professional tennis players, Working Paper, Boston Univ.

Roberts, T.A., and Nolen-Hoeksama S. (1989), "Sex Differences in Reactions to Evaluative Feedback", Sex Roles, XXI (1989), pp. 725-747.

Wozniak, D. (2012), Gender differences in a market with relative performance feedback: Professional tennis players, Journal of Economic Behavior \& Organization, 83(1), 158-171.

Wozniak, D., Harbaugh, W. T., and Mayr, U. (2014). The menstrual cycle and performance feedback alter gender differences in competitive choices. Journal of Labor Economics, 32(1), 161-198. 


\section{Appendix}

Our results are robust also when we consider as a dependent variable the probability of winning the second set. In Table A1 are reported the first three specifications reported in Table 3.

Table A1. Probability of Winning the Second Set. Linear Probability Model

\begin{tabular}{|c|c|c|c|}
\hline & (1) & (2) & (3) \\
\hline \multirow[t]{2}{*}{ Lost I set } & $-0.205 * * *$ & $-0.204 * * *$ & $-0.204 * * *$ \\
\hline & $(0.008)$ & $(0.008)$ & $(0.008)$ \\
\hline \multirow[t]{2}{*}{ Female } & 0.008 & & 0.005 \\
\hline & $(0.016)$ & & $(0.017)$ \\
\hline \multirow[t]{2}{*}{ Female*Lost I set } & $-0.029 * * *$ & $-0.028 * *$ & $-0.029 * * *$ \\
\hline & $(0.011)$ & $(0.011)$ & $(0.011)$ \\
\hline \multirow[t]{2}{*}{ Prob. Win A } & $0.687 * * *$ & $0.674 * * *$ & $0.687 * * *$ \\
\hline & $(0.018)$ & $(0.021)$ & $(0.018)$ \\
\hline \multirow[t]{2}{*}{ Female*(Prob. Win A) } & 0.014 & 0.013 & 0.012 \\
\hline & $(0.023)$ & $(0.027)$ & $(0.023)$ \\
\hline Controls: Rest Diff; Ranking A; & YES & YES & YES \\
\hline \multicolumn{4}{|l|}{ Surfaces; Round; Year; Month } \\
\hline Tournament fixed effects & NO & NO & YES \\
\hline Player fixed effects & NO & YES & NO \\
\hline Observations & 35152 & 35152 & 35152 \\
\hline Adjusted R-squared & 0.196 & 0.193 & 0.196 \\
\hline
\end{tabular}

Notes: The Table reports OLS estimates. The dependent variable is Win II Set. Standard errors (reported in parentheses) are corrected for heteroskedasticity. The symbols ***, **, * indicate that coefficients are statistically significant, respectively, at the 1,5 , and 10 percent level.

In Table A2 we model the probability of winning the third set. Again our main findings remain substantially unchanged.

Table A2. Probability of Winning the Third Set. Linear Probability Model

\begin{tabular}{lccc}
\hline & $(1)$ & $(2)$ & $(3)$ \\
\hline Lost II set & $-0.053^{* * *}$ & $-0.049^{* * *}$ & $-0.052^{* * *}$ \\
& $(0.013)$ & $(0.013)$ & $(0.013)$ \\
Female & $0.062^{* *}$ & & $0.057^{* *}$ \\
& $(0.025)$ & $(0.027)$ & 0.010 \\
Female*Lost II set & 0.010 & 0.011 & $(0.018)$ \\
& $(0.018)$ & $(0.019)$ & $0.802^{* * *}$ \\
Prob. Win A & $0.801 * * *$ & $0.758^{* * *}$ & $(0.031)$ \\
& $(0.031)$ & $(0.038)$ & $-0.113^{* * *}$ \\
Female*(Prob. Win A) & $-0.108^{* * *}$ & -0.069 & $(0.042)$ \\
& $(0.041)$ & $(0.051)$ & YES \\
\hline Controls: Rest Diff; Ranking & A; & YES & \\
Surfaces; Round; Year; Month & & NO & YES \\
Tournament fixed effects & NO & YES & NO \\
Player fixed effects & 11629 & 11629 & 11629 \\
\hline Observations & 0.093 & 0.094 & 0.093 \\
Adjusted R-squared & & & \\
\hline \hline
\end{tabular}

Notes: The Table reports OLS estimates. The dependent variable is Win II Set. Standard errors (reported in parentheses) are corrected for heteroskedasticity. The symbols $* * *, * *, *$ indicate that coefficients are statistically significant, respectively, at the 1,5 , and 10 percent level. 